\title{
DESIGNING AN EXPERIMENT FOR EVALUATING SEATING POSITIONS IN PARALYMPIC ROWING
}

\author{
S. W. Eikevåg ${ }^{凶}$, A. Kvam, M. K. Bjølseth, J. F. Erichsen and M. Steinert \\ Norwegian University of Science and Technology, Norway \\ $\triangle$ sindrwe@stud.ntnu.no
}

\begin{abstract}
When designing high performance sports equipment for Paralympic athletes, there are many unknowns for the design engineer to consider. The design challenge is an optimisation task per individual athlete. However, modelling this optimisation is difficult due to the many variables. This article presents the design of an experiment for identifying and evaluating various seating positions in Paralympic rowing by using a rowing ergometer with a modified seat. Results indicate that changing seating position has a substantial impact on per-athlete rowing performance.
\end{abstract}

Keywords: paralympic rowing, prototyping, design evaluation, sports engineering, optimisation

\section{Introduction and background}

When designing high performance sports equipment for the human body, biomechanical models and simulations are often used to optimize the gear for the various functionalities and performance such as speed, weight, friction etc. Engineering designers can build on a vast and well-established foundation of anatomical and medical knowledge from sport science, engineering and medicine (Shan, 2008). In essence, the engineering design task is an (albeit often complicated) optimization task to solve various known dependent and independent variables with known or estimated interdependencies.

Paralympic athletes however change that design challenge fundamentally. Though there are fixed disability classes for various Paralympic disciplines, the actual motoric abilities of the various athletes differ quite substantially. What is more, the exact amount of muscle activation (which muscles and with how much force) per individual is not fully known. Hence, the design problem turns into a complex problem where we do not have full control or knowledge of and about all influencing variables and how they impact performance. Therefore, high performance gear cannot be optimized in a straightforward fashion, e.g. simulations. Instead we propose and test a heuristic and iterative approach that combines physical testing with tight user integration. The initial performance gains in our test case, Paralympic rowing, are remarkable and very promising.

Paralympic rowing is divided into three classes, depending on impairment and the number of athletes per boat. The classes are differentiated by the severity of the impairment of the athlete, ranging from athletes who can make use of a slidable seat (PR3), to athletes with a functional trunk but not able to use a slidable seat (PR2), and athletes having minimal or no trunk function (PR1). Which class an athlete is assigned to is determined by The World Rowing Federation (FISA, 2017). The boats used in the PR1 class are called sculls and are differentiated from sculls used by fully functional athletes in the sense that they are more stable to prevent capsizing. This increased stability is obtained by using a 
wider hull profile, and pontoons located on each side of the hull, at a minimum of $60 \mathrm{~cm}$ from the centreline of the hull. Like in able-bodied Olympic rowing, the sculls are designed from standardised profiles. Figure 1 shows a scull used in the Paralympic rowing class PR1 during the 2019 season. The rules (FISA, 2017) state that the PR1 athlete should be fixed to the seat by at least one strap secured to the seatback, and around the trunk. Additional straps are allowed provided they comply with the rules (FISA, 2017). In addition to the mandatory trunk strap, many PR1 athletes use one strap around the knees to reduce the (intentional and unintentional) movement in the seat.

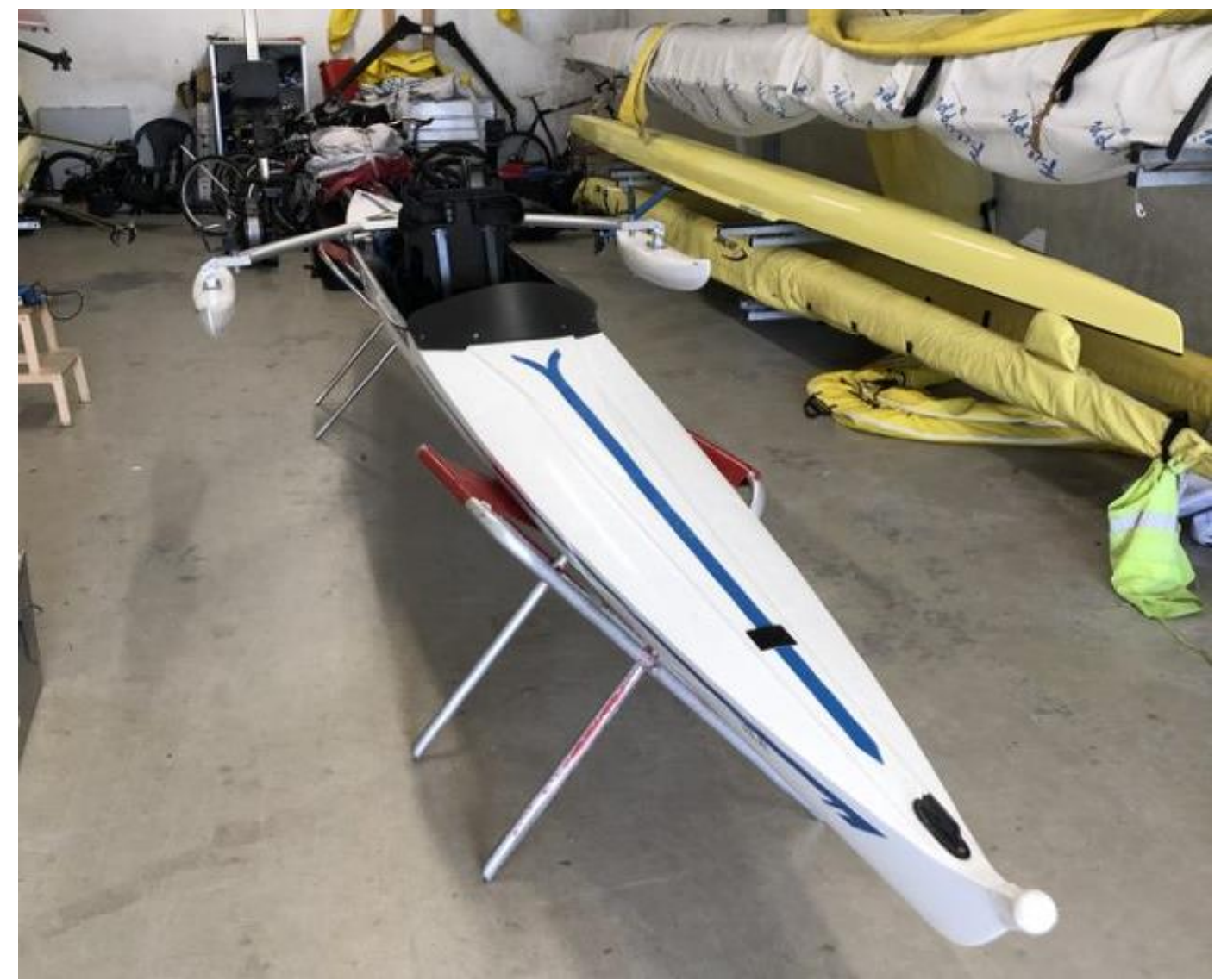

Figure 1. Scull used in the Paralympic rowing class PR1 during the 2019 season.

When investigating other Paralympic disciplines, e.g. cycling or cross-country skiing, adapting the equipment to the individual athlete is crucial (Mâsse et al., 1992; Rapp et al., 2016; Too, 1991). This is further backed up from observations made during competitions. From other Paralympic sports, e.g. wheelchair propulsion and cross-country skiing, there are studies showing that changing the sitting position does affect athlete performance (Jeukendrup and Diemen, 1998; Mâsse et al., 1992; Rapp et al., 2016). Among world-leading Paralympic rowers, there is a wide range of different individual seating configurations and positions between different athletes. However, how the different designs affect athlete performance is still not fully understood. Understanding the interaction between athlete and equipment is key to solve the design problem, i.e. designing high performance sports equipment for Paralympic rowing.

The aim of this paper is to present how an experiment was designed to identify better seating positions for a specific Paralympic rower on a rowing ergometer, by measuring and comparing heart rate, lactate and strokes per minute. The design of the experiment also includes the design of equipment necessary to conduct the experiment, in this case, a seat for a rowing ergometer facilitating various seating positions. While the experiment is designed for identifying athlete performance at various seating positions on a rowing ergometer, the overarching research objective of this work is to use this experiment for understanding athlete performance and evaluating subsequent seat designs for sculls used in Paralympic rowing. 


\section{Experiment design}

An experiment has been designed to identify rowing performance at various seating positions for one specific Paralympic athlete. This section describes the method used for designing the experiment, including the equipment used, chosen experiment procedure, as well as metrics for evaluation.

\subsection{Equipment design and setup}

Ideally, it would be nice to experiment on various seating positions by testing the athlete using a scull on water. However, testing the already complicated athlete-equipment system in its intended environment further adds complexity to the testing (Winjum et al., 2017). Weather, wind, underwater currents and other conditions add to the many variables and unknowns. Furthermore, testing on water complicates the data collection from physiological measurements. Therefore, it was decided to design an experiment using a rowing ergometer. It was decided to use a Concept2 Model D rowing ergometer, to ensure comparable results in terms of produced work, and because this was the specific type of rowing ergometer used by the athlete for indoor training. Current rowing ergometers are developed for ablebodied athletes and there are various adaptations for Paralympic rowers that exchange the moving seat with a fixed seat, exemplified in Figure 2. Such seat designs often incorporate adjustability to account for the athlete leg length, and have some adjustability on the back rest angle.

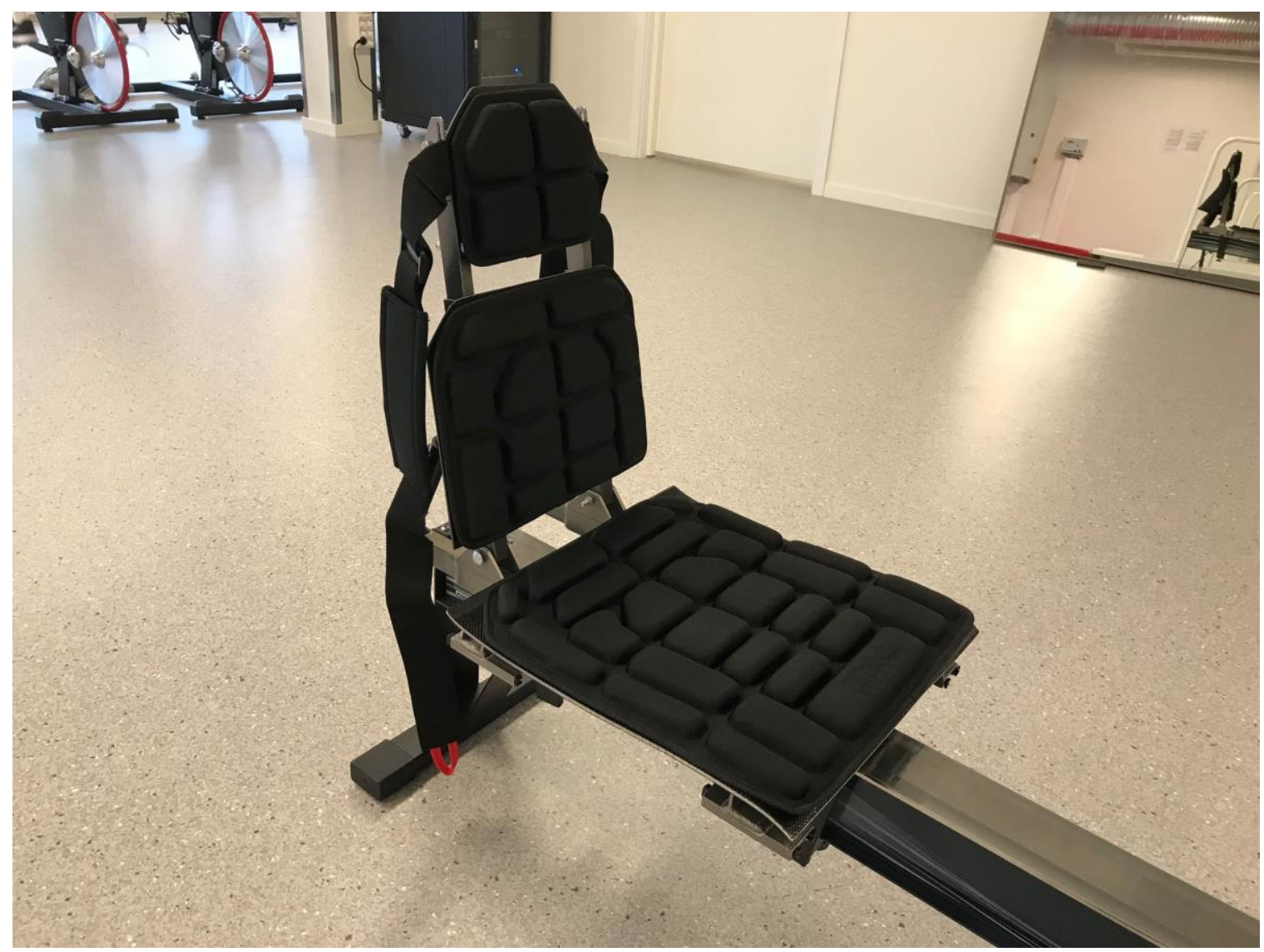

Figure 2. Rowing ergometer adapted for PR1 Paralympic rowers by installing a fixed seat

To allow for experimenting with various seating positions on the rowing ergometer, a custom seat had to be designed, with design requirements specific to this experiment setup. Firstly, the seat had to be designed to fit the seating rail of the Concept 2 rowing ergometer. Secondly, the seat had to be adjustable so that the position currently used in the athlete's scull could be tested against new positions, including the aforementioned safety strapping. This enables comparison between new seating positions, and the current position. Thirdly, the equipment had to facilitate a wide range of seating positions suitable for the athlete, and the possibility to rapidly change from one position to 
another. Lastly, the seat should also be able to withstand the forces generated by the athlete when rowing at competition pace without breaking or causing extensive compliance to it.

The design of the equipment was an iterative process similar to what is described by Jensen et al. (2017), initiated by sketch drawings of different concepts fulfilling the abovementioned design requirements. Simple prototypes were created to compare different concepts up against each other. After an evaluation based on production feasibility, the number of adjustment possibilities, and the ability to handle the relevant forces, the final seating assembly was created, and consisted of three parts; seatback, seat plate and thigh support. The adjustability of the individual components is summarized in Table 1 . The main material used in the experimental seat was wood, except some parts made of steel and aluminium for structural purposes. Figure 3 depicts the experimental seat mounted on the Concept 2 rowing ergometer. The iterative nature of the prototyping process and the low fidelity of the prototypes (as defined by Lim et al. (2008)) enabled rapid design and production of the equipment able to satisfactory conduct the experiment.

Table 1. The adjustability of the individual parts of the prototype assembly

\begin{tabular}{|l|l|l|}
\hline Part & Adjustability & Dimensions (Table 2) \\
\hline Seatback & Longitudinal (fixed to seat) and angle & Angle $=$ A \\
\hline Seat & Longitudinal and angle & Angle $=$ B \\
\hline Thigh support & Longitudinal, height and angle & Angle $=$ C, Height $=$ D \\
\hline
\end{tabular}

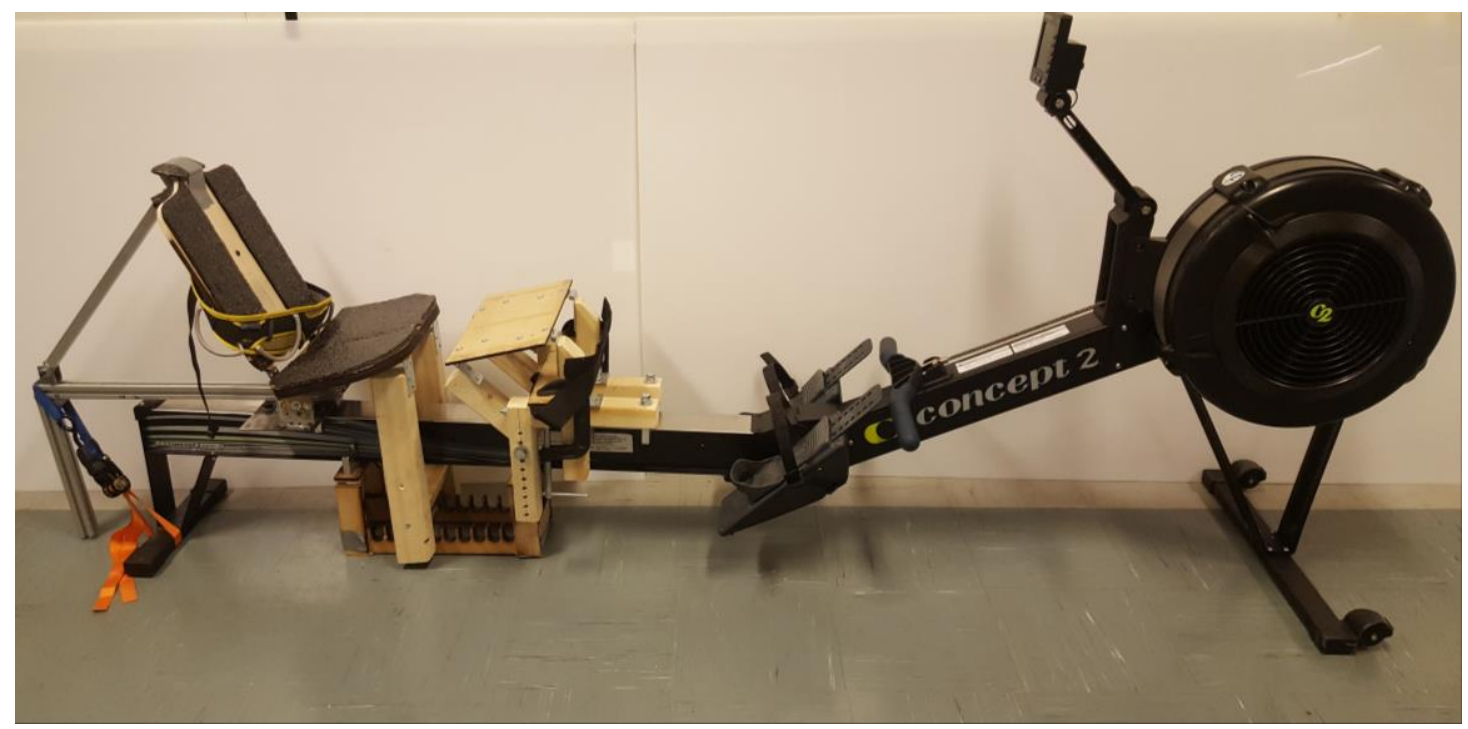

Figure 3. The experimental equipment mounted on a Concept2 rowing ergometer

\subsection{Developing the experiment procedure}

The experiment procedure was worked out in cooperation with the Paralympic athlete, the athlete's coach and physical therapist. Prior to the experiment, the effect of an adjustable seat on rowing performance was unknown. A heuristic and iterative approach was applied in order to qualitatively choose which seating positions to use in the experiment. Extremities of the adjustability was pretested, both steep and shallow angles. This formed the basis for limits at both ends, together with the athlete's range of motion and the maximum adjustability of the seat. Within this range, a variety of different positions were briefly pre-tested qualitatively by having the athlete using the equipment and noting which positions gave which outputs and feel (based on the athlete's feedback). This rapid pretesting of many seating positions was made possible by the quick and easy way of adjusting the prototype to the desired position. The results from this rapid pre-testing made the foundation of the following experiment. 
To be able to measure the effect on the athlete's efficiency with different seat configurations, the following experiment procedure (Figure 5) was established: A 10 minute warmup at low intensity, followed by three sets of 4 minutes at increasing power targets; 50, 70 and 90 watts with the Concept2 rowing ergometer set at resistance level 1 (i.e. the lowest resistance). The athlete was to perform the same tests with each three different seating configurations, Position 1 (Figure 4), Position 2 (Figure 6) and Position 3 (Figure 7). Between each set the athlete rested for one minute. Similar test intervals were used by Baumgart et al. (2018) when comparing peak oxygen uptake and exercise efficiency between upper-body poling and arm crank ergometry in trained paraplegic and able-bodied participants.

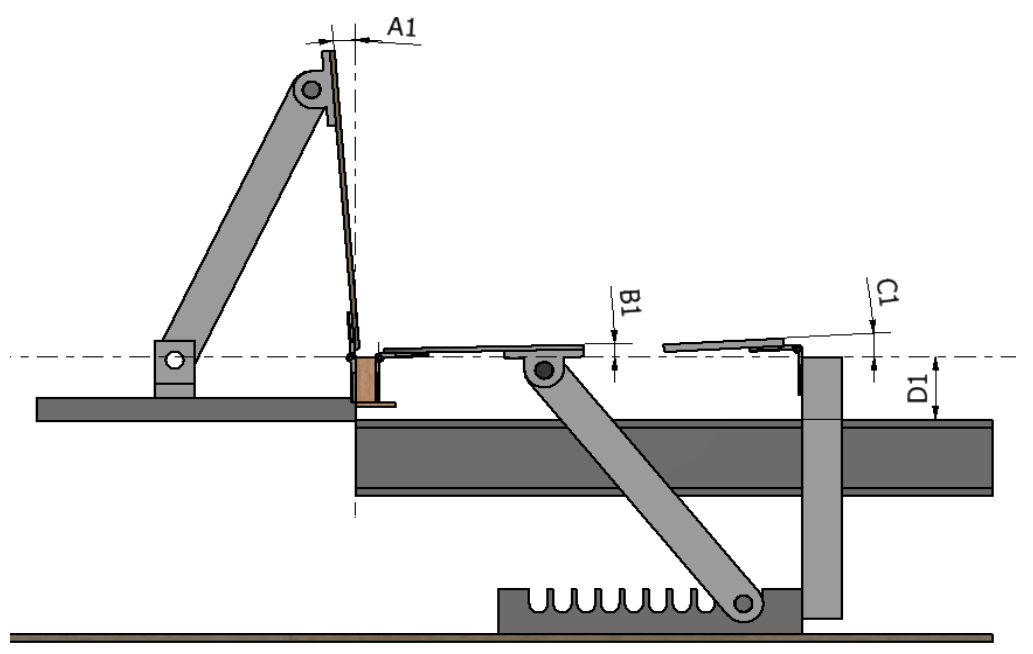

Figure 4. Position 1

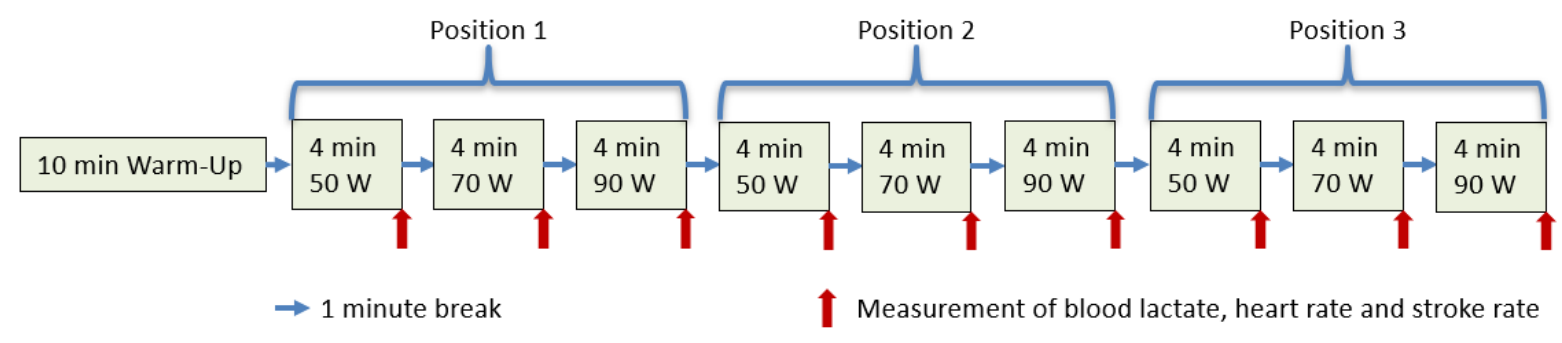

Figure 5. Experiment procedure

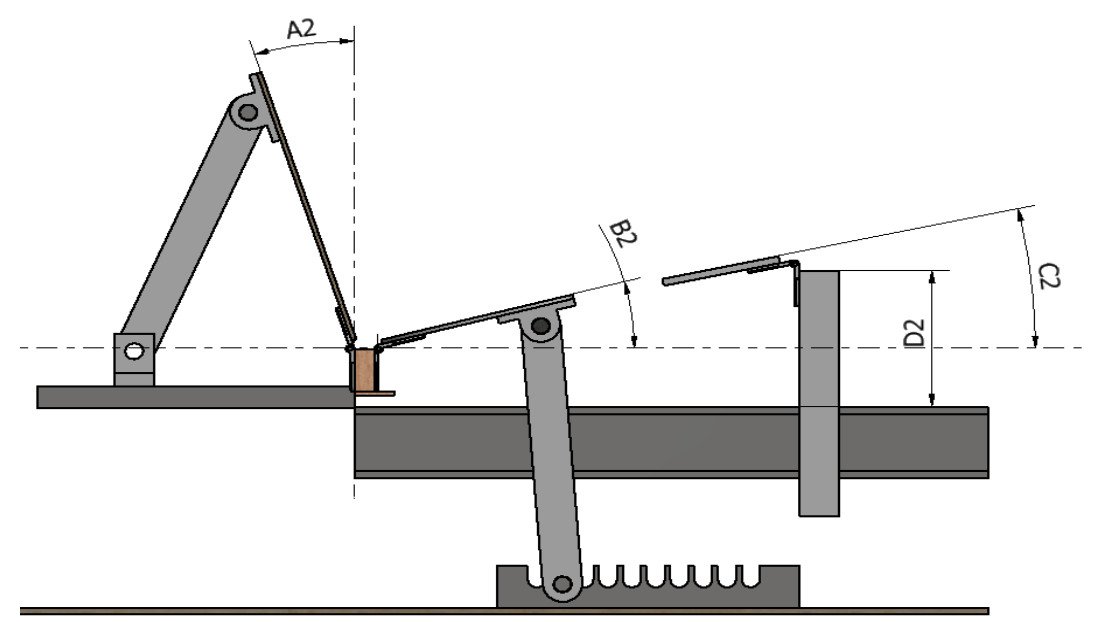

Figure 6. Position 2 
During the experiment, the seatback was adjusted downward (shallower angle) in consistent intervals. The first position tested (Position 1, seen in Figure 4) was chosen to replicate the position the athlete currently uses in the competition boat, and was used as a benchmark for the remaining positions which had varying angles at the seat, seat back and thigh support. This setup used the smallest angles of the experiment (A1, B1, C1) and tight support closest to the Concept2 rail (D1) as shown in Figure 4. In Position 2 (Figure 6) the angle was set to A2, an angle between the benchmark angle (position 1) and the most promising angle tested the previous day (Position 3, seen in Figure 7). The seat bottom angle B2 was set to match the seatback with a component angle of 90 degrees. The thigh support (C2, D2) was adjusted to match the seat bottom angle. Position 3 (Figure 7) was the most extreme position, but also what the coach and physiotherapist most believed in. They said that this looked like a strong position and unofficially did best the previous day. This position was close to the athlete's range of motion limit, thus going past this there would be problems getting back up. The seat angle B3 was changed minimal from position 2 to increase the total angle. A minimal change in the seat angle resulted in $\mathrm{C} 2=\mathrm{C} 3$ and $\mathrm{D} 2=\mathrm{D} 3$.

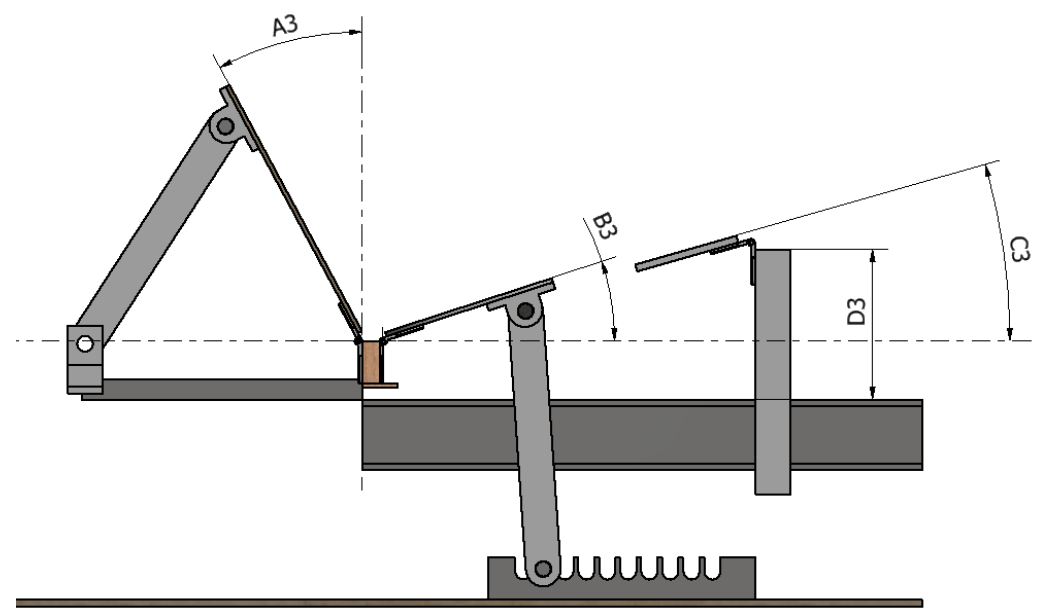

Figure 7. Position 3

\subsection{Data collection and metrics for evaluation}

To evaluate the technical proficiency, the expert opinion from the coach and the physio was consulted. To evaluate rowing performance, measuring the mean heart rate (beats per minute), lactate concentration $(\mathrm{mg} / \mathrm{dL})$ and mean stroke rate (strokes per minute) was chosen in order to differentiate the effect of the chosen seating positions. In addition to measurable values, the Paralympic athlete's user feedback was an important factor noted during the experiment which could be seen in context with the numerical results.

The equipment used to measure the four quantities where evaluated according to availability and accuracy. The heart rate was measured using a Polar Vantage V watch. There is not much research on this specific model, but it is stated that earlier models of this brand are valid devices for monitoring heart rate (Caminal et al., 2018; Lee and Gorelick, 2011). Lactate level was measured from a blood sample extracted from the finger, using a Lactate pro 2. This device evaluated by Tanner et al. (2010) displays good reliability and accuracy compared to a laboratory-based analyser. Stroke frequency and power output were measured using the Concept2 Model D rowing machine with a PM5 performance monitor. According to Boyas et al. (2006), this system underestimates the power by approximately $25 \mathrm{~W}$ but gives stable and consistent readings.

\section{Results}

The experiment described in the previous section was tested by the Paralympic rower in October 2019. The athlete performed three sets of 4 minutes at a power target of 50, 70 and 90 watts for each of the three seating positions. The results from the experiment and warmup are shown in Table 2. 
Table 2. Duration, target power, mean power output, mean percentage of maximum heart rate, lactate concentration and stroke rate for the various tests conducted in the experiment

\begin{tabular}{|c|c|c|c|c|c|c|}
\hline & $\begin{array}{l}\text { Duration } \\
\text { [min] }\end{array}$ & $\begin{array}{c}\text { Target } \\
\text { Power } \\
\text { [W] }\end{array}$ & $\begin{array}{l}\text { Mean Power } \\
\text { Output [W] }\end{array}$ & $\begin{array}{l}\text { Mean Percentage of } \\
\text { Maximum Heart Rate }\end{array}$ & $\begin{array}{c}\text { Lactate Concentration } \\
{[\mathrm{mg} / \mathrm{dL}]}\end{array}$ & $\begin{array}{l}\text { Mean Stroke } \\
\text { Rate [1/min] }\end{array}$ \\
\hline Warmup & 10 & $\mathrm{n} / \mathrm{a}$ & 43 & $\mathrm{n} / \mathrm{a}$ & 1.5 & $\mathrm{n} / \mathrm{a}$ \\
\hline \multirow{3}{*}{ Position 1} & 4 & 50 & 51 & $69 \%$ & 1.9 & 26 \\
\hline & 4 & 70 & 68 & $78 \%$ & 2.4 & 31 \\
\hline & 4 & 90 & 89 & $87 \%$ & 4.6 & 32 \\
\hline \multirow{3}{*}{ Position 2} & 4 & 50 & 53 & $64 \%$ & 2 & 20 \\
\hline & 4 & 70 & 70 & $76 \%$ & 2 & 22 \\
\hline & 4 & 90 & 90 & $81 \%$ & 2.4 & 28 \\
\hline \multirow{3}{*}{ Position 3} & 4 & 50 & 50 & $64 \%$ & 1.4 & 22 \\
\hline & 4 & 70 & 70 & $68 \%$ & 1.4 & 23,5 \\
\hline & 4 & 90 & 90 & $77 \%$ & 2.1 & 27,5 \\
\hline
\end{tabular}

Based on the experiment, three bar charts have been created to compare mean produced percentage of maximum heart rate, lactate concentration and stroke frequency for the different seating positions at the various target power levels. These are shown in Figure 8, Figure 9 and Figure 10.

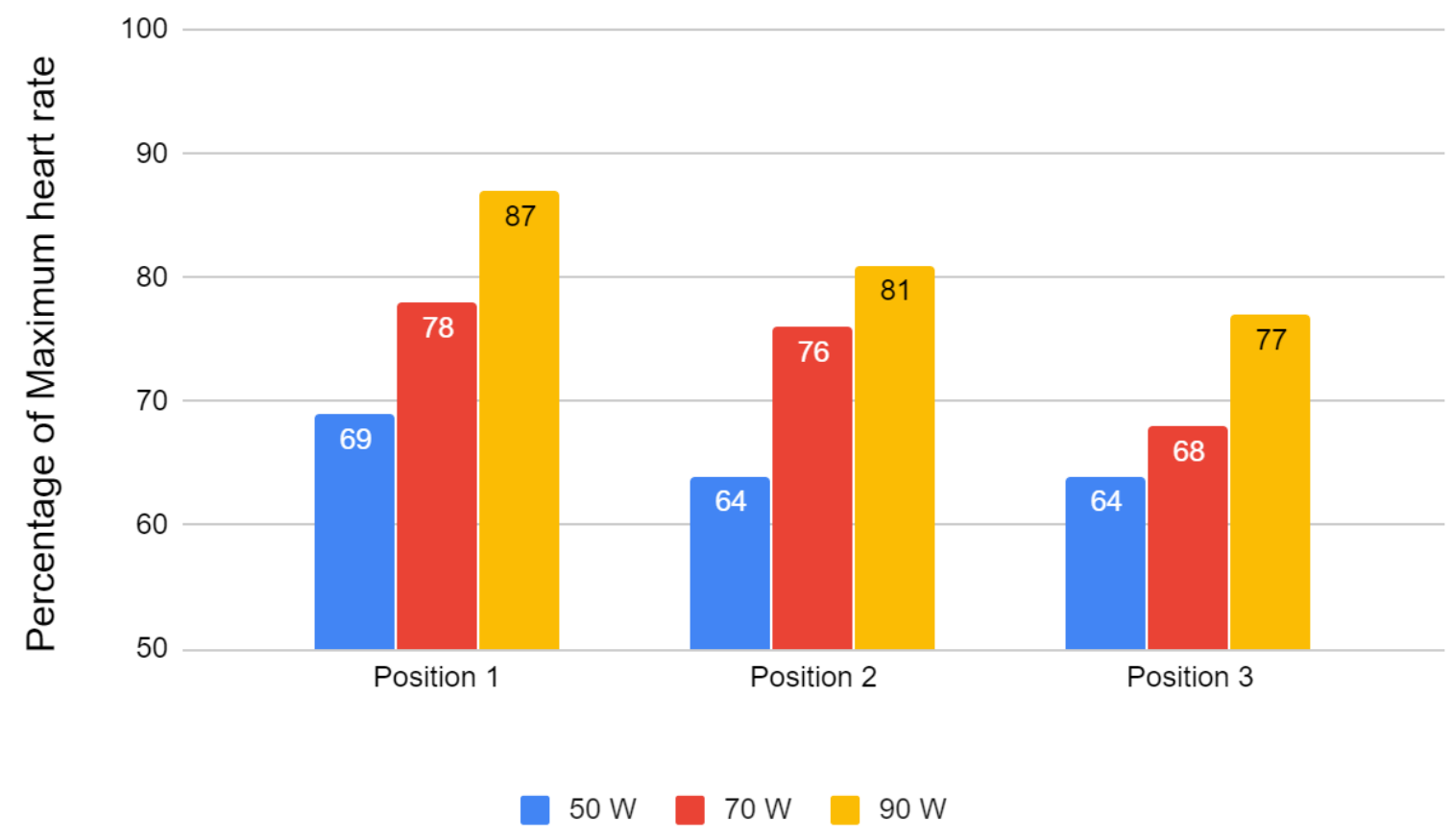

Figure 8. Mean percentage of maximum heart rate at $50 \mathrm{~W}, 70 \mathrm{~W}$ and $90 \mathrm{~W}$ power targets 
5

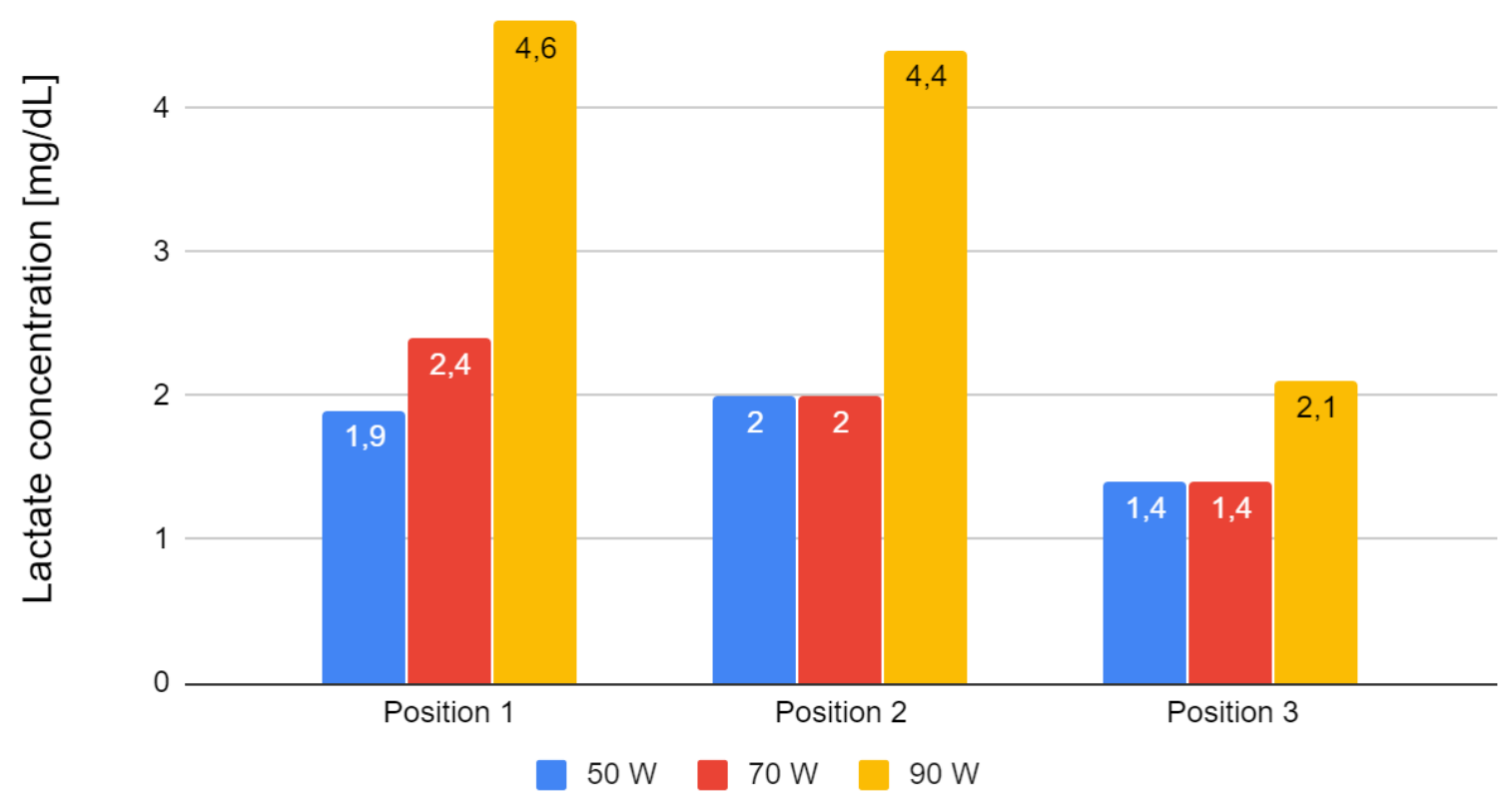

Figure 9. Lactate concentration at 50W, $70 \mathrm{~W}$ and $90 \mathrm{~W}$ power targets

\section{Stroke rate at $50 \mathrm{~W}, 70 \mathrm{~W}$ og $90 \mathrm{~W}$}

40

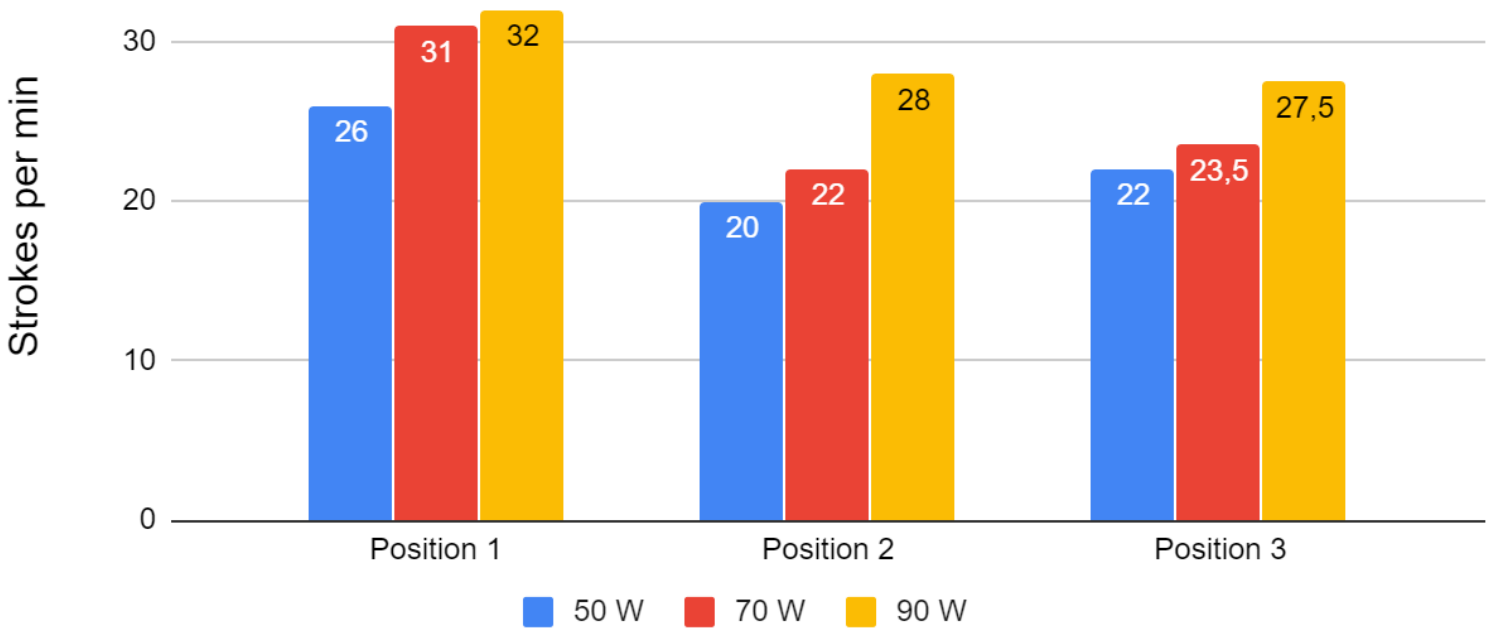

Figure 10. Mean stroke rate at 50W, $70 \mathrm{~W}$ and $90 \mathrm{~W}$ power targets

\section{Discussion}

Comparing the results from all positions, the average heart rate observed at the different power targets differ greatly between seating configurations. At $90 \mathrm{~W}$ target power, the percentage of maximum heart rate was reduced by 10 percentage points from Position 1 to 3 , from $87 \%$ of max heart rate to $77 \%$ of max heart rate. The difference in lactate was even greater than the heart rate. When comparing 
Position 1 and 3, the lactate dropped 54\% from 4,6 to 2,1 at 90W. The mean stroke rate needed to maintain the target power output of 90 watts was reduced by $14 \%$ from 32 strokes per minute to 27,5 strokes per minute.

A Concept 2 model D PM5 performance monitor was used to measure the mean power. Boyas et al. (2006) claim that this ergometer underestimates the power produced by the rower by approximately $25 \mathrm{~W}$. This is argued to be relatively consistent in both low and high-power values. As these experiments looked for changes in performance between the different seating positions, this consistent deviation does not affect the findings noticeable. The mean power measured, as seen in Table 2 , deviates slightly from the target values, as the athlete was unable to maintain a consistent watt level throughout the set. This small deviation is expected as normal rower variability on this rowing machine and will be neglected for rest of this paper.

The drastic difference in lactate at $90 \mathrm{~W}$ target power could be explained by the athlete operating in her anaerobic zone in Position 1 and 2, i.e. above her anaerobic threshold. This may cause her to build up lactate acid in the blood during these tests, while in Position 3 she operates in her aerobic zone, giving no lactate build up (Davis et al., 1976; Messonnier et al., 2013).

The reduction in stroke frequency at $90 \mathrm{~W}$ between Position 1 and 3 may indicate a better power output per stroke efficiency, as she is able to produce same watt output with a lower stroke rate, meaning that she may be producing more power per stroke. The increased power output per stroke could be a result of a longer stroke provided by the seating position. This has however not been measured and could not be verified in this experiment.

Heart rate provides a good indication of the power output of the body (Arts and Kuipers, 1994; Grazzi et al., 1999; Lucía et al., 2000). However, the heart rate may change from day to day, and is dependent on various factors i.e. hours of sleep, or if the athlete has been drinking coffee. Many of these factors might be neglected as the experiment was performed during a short period of time (approximately 2 hours).

\section{Implications and further work}

The results shown are promising, despite the limited amount of data. For future development, more testing at multiple days, with the athlete is desired. Both regarding several data points from the same seating position at a given power output as well as a larger resolution on the gradient of the angles adjusted. With a larger set of tests performed at different times, the factor of daily performance can then also be considered.

With further testing, the order in which the tests are performed can be randomised and a potential build-up of lactate as well as the athlete becoming tired can be neglected as a source of error. By conducting more tests, the experiment can be performed with only one variable changing at a time. Then, a comparison could be made between the effect of changing the seatback angle and the seat plate, to validate which degree of freedom that affects performance the most. Such a seat bottom can be optimized first, with a constant seat back angle, before experimenting with an increment of seat back angles. This would further increase the quality of the experiments.

\section{Conclusion}

In this article, the design of an experiment for evaluating various seating positions in Paralympic rowing has been described, including the necessary equipment for testing and evaluating said seating positions, and analysis of preliminary results have been presented and analysed. From examining the results, it is evident that adjusting the seating position had a major impact on the Paralympic athlete's rowing performance. From the least to the most efficient position, a decrease in all measured performance indicators was noted during all target power levels. This clearly shows an improvement towards this specific athlete's optimal seating position for the most effective working economy. However, the optimal position cannot be concluded to have been found. For this to be achieved, additional experiments with a higher resolution of adjustment as well as segregation of angle adjustment need to be performed. This paper illustrates how to guide development towards an optimal position. 


\section{References}

Arts, F.J.P. and Kuipers, H. (1994), “The Relation Between Power Output, Oxygen Uptake and Heart Rate in Male Athletes", International Journal of Sports Medicine, Vol. 15 No. 5, pp. 228-231.

Baumgart, J.K. et al. (2018), "Comparison of peak oxygen uptake and exercise efficiency between upper-body poling and arm crank ergometry in trained paraplegic and able-bodied participants", European Journal of Applied Physiology, Vol. 118 No. 9, pp. 1857-1867.

Boyas, S. et al. (2006), "Power Responses of a Rowing Ergometer: Mechanical Sensors vs. Concept2® Measurement System”, International Journal of Sports Medicine, Vol. 27 No. 10, pp. 830-833.

Caminal, P. et al. (2018), "Validity of the Polar V800 monitor for measuring heart rate variability in mountain running route conditions", European Journal of Applied Physiology, Vol. 118 No. 3, pp. 669-677.

Davis, J.A. et al. (1976), "Anaerobic threshold and maximal aerobic power for three modes of exercise", Journal of Applied Physiology, Vol. 41 No. 4, pp. 544-550.

Grazzi, G. et al. (1999), "The power output/heart rate relationship in cycling: test standardization and repeatability", Medicine and Science in Sports and Exercise, Vol. 31 No. 10, pp. 1478-1483.

Jensen, M.B., Elverum, C.W. and Steinert, M. (2017), "Eliciting unknown unknowns with prototypes: Introducing prototrials and prototrial-driven cultures | Elsevier Enhanced Reader", March, https://doi.org/ 10.1016/j.destud.2016.12.002

Jeukendrup, A. and Diemen, A.V. (1998), "Heart rate monitoring during training and competition in cyclists", Journal of Sports Sciences, Vol. 16 No. sup1, pp. 91-99.

Lee, C.M. and Gorelick, M. (2011), "Validity of the Smarthealth Watch to Measure Heart Rate During Rest and Exercise”, Measurement in Physical Education and Exercise Science, Vol. 15 No. 1, pp. 18-25.

Lim, Y.-K., Stolterman, E. and Tenenberg, J. (2008), "The Anatomy of Prototypes: Prototypes As Filters, Prototypes As Manifestations of Design Ideas", ACM Trans. Comput.-Hum. Interact, Vol. 15 No. 2, pp. 7:1-7:27.

Lucía, A. et al. (2000), "Heart rate and performance parameters in elite cyclists: a longitudinal study", Medicine \& Science in Sports \& Exercise, Vol. 32 No. 10, pp. 1777-1782.

Mâsse, L.C., Lamontagne, M. and O'riain, M.D. (1992), "Biomechanical analysis of wheelchair propulsion for various seating positions", Journal of Rehabilitation Research and Development, Vol. 29 No. 3, pp. 12-28.

Messonnier, L.A. et al. (2013), "Lactate kinetics at the lactate threshold in trained and untrained men", Journal of Applied Physiology, Vol. 114 No. 11, pp. 1593-1602.

Rapp, W. et al. (2016), "Role of muscle activation in the sit-skiing performance and classification process", p. 11.

Shan, G. (2008), "Sport Equipment Evaluation and Optimization - A Review of the Relationship between Sport Science Research and Engineering”, https://doi.org/10.2174/1875399x00801010005.

Tanner, R.K., Fuller, K.L. and Ross, M.L.R. (2010), "Evaluation of three portable blood lactate analysers: Lactate Pro, Lactate Scout and Lactate Plus”, European Journal of Applied Physiology, Vol. 109 No. 3, pp. 551-559.

Too, D. (1991), "The Effect of Hip Position/Configuration on Anaerobic Power and Capacity in Cycling", https://doi.org/10.1123/ijsb.7.4.359.

Winjum, J. et al. (2017), "A Heuristic Approach for Early-Stage Product Development in Extreme Environments", Presented at the IEEE International Conference on Engineering, Technology and Innovation 2017, IEEE, Madeira. 